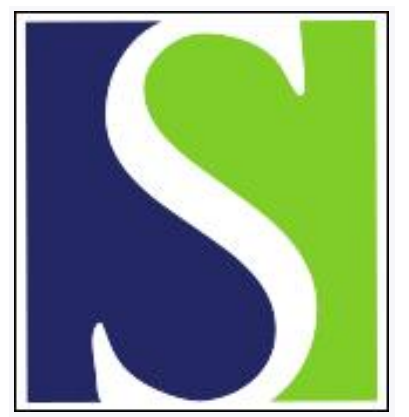

Scand J Work Environ Health 2018;44(3):303-311

https://doi.org/10.5271/sjweh.3714

Published online: 02 Feb 2018, Issue date: 01 May 2018

Relationship between parents' occupational characteristics and untreated dental caries in offspring: A population-based study of data from the Korean National Health and Nutrition Examination Survey, 2008-2015

by Lim S-S, Kim B, Yoon J-H, Song JS, Park E-C, Jang S-I

The children of non-white-collar (pink-, blue-collar) workers, non-wage earners (self-employed workers/employers, and unpaid family workers) and of workers who work overtime hours or shift work are at risk of untreated dental caries. The effects of the parents' occupational characteristics on untreated dental caries differed by sex (mother versus father). Dental caries prevention programs targeting children should consider parental occupational characteristics.

Affiliation: Department of Preventive Medicine, Institute of Health Services Research, Yonsei University College of Medicine, 50 Yonsei-ro, Seodaemun-gu, Seoul 120-752, Republic of Korea. jangsi@yuhs.ac

Refers to the following texts of the Journal: 2017;43(1):59-67 2013;39(6):559-567

Key terms: children; dental caries; dental healthcare; Korea; Korean National Health and Nutrition Examination Survey; occupational characteristic; offspring; oral health; parent; parent-child relationship; pediatric oral health; population-based study; work-life balance

This article in PubMed: www.ncbi.nlm.nih.gov/pubmed/29392328

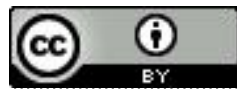




\title{
Relationship between parents' occupational characteristics and untreated dental caries in offspring: A population-based study of data from the Korean National Health and Nutrition Examination Survey, 2008-2015
}

\author{
by Sung-Shil Lim, MD, 1, 2, 3 Byurira Kim, DDS, ${ }^{4}$ Jin-Ha Yoon, MD, 1, 2, 3, Je Seon Song, DDS, ${ }^{4,6}$ Eun-Cheol Park, MD, 5,7 \\ Sung-In Jang, $M D_{,}^{5,7}$
}

Lim S-S, Kim B, Yoon J-H, Song JS, Park E-C, Jang S-I. Relationship between parents' occupational characteristics and untreated dental caries in offspring: A population-based study of data from the Korean National Health and Nutrition Examination Survey, 2008-2015. Scand J Work Environ Health. 2018:44(3):303-311. doi:10.5271/sjweh.3714

\begin{abstract}
Objectives We investigated the association between parents' occupational characteristics and untreated dental caries in their children.

Methods We analyzed the data of 4764 and 5862 children merged with data of their mothers and fathers, respectively, derived from the Korean National Health and Nutrition Examination Survey, 2008-2015. Dentists assessed untreated dental caries, and occupational characteristics were self-reported. The associations between untreated dental caries in children and their parents' occupational characteristics were assessed with logistic regression analysis.
\end{abstract}

Results The prevalence of untreated dental caries was $18.58 \%$ and $16.39 \%$ in the mother- and father-matched data, respectively. Compared to children whose mothers worked regular hours, those whose mothers worked overtime had increased odds of untreated dental caries [odds ratio (OR) 1.19, 95\% confidence interval (CI) 1.02-1.39]. Children of female self-employed workers/employers/unpaid family workers had higher odds of untreated dental caries than those of wage earners (OR 1.18, 95\% CI 1.00-1.39). The OR of untreated dental caries was higher among children with shift-working parents than those whose parents worked daytime hours (mother: OR 1.29, 95\% CI 1.11-1.51; father: OR 1.36, 95\% CI 1.18-1.58).

Conclusions The children of non-white-collar workers, non-wage earners, and workers working overtime or doing shift work had higher odds of untreated dental caries. The effects of parental occupational characteristics on untreated dental caries differed by sex (mother versus father). Public health programs targeting the prevention of dental caries among children should consider parental occupational characteristics.

Key terms children; dental healthcare; Korea; oral health; parent-child relationship; pediatric oral health; worklife balance.

Dental caries is one of the most prevalent and contagious chronic diseases worldwide (1). It is caused by acidproducing bacteria that lower the acidity of the mouth and cause mineral loss in the teeth (2). Dental caries is the most common cause of permanent tooth extraction $(3,4)$. Extracting the permanent teeth of children should be avoided due to their remaining lifespan and the cost of dental implants.
Strategies for the prevention of dental caries have focused on children because the high public health burden of dental caries at all ages can be lowered if they are prevented during childhood (5). Although the prevalence of dental caries in 12-year-old children in Korea has been declining (6), it is higher than that in other developed countries (7). The decayed, missing, filled teeth (DMFT) index, one of the most common

1 Graduate School of Public Health, Yonsei University, Seoul, Republic of Korea

2 The Institute for Occupational Health, Yonsei University College of Medicine, Seoul, Republic of Korea.

3 Incheon Workers' Health Center, Incheon, Republic of Korea.

4 Department of Pediatric Dentistry, College of Dentistry, Yonsei University, Seoul, Republic of Korea.

5 Department of Preventive Medicine and Public Health, Yonsei University College of Medicine, Seoul, Republic of Korea.

6 Oral Science Research Center, College of Dentistry, Yonsei University, Seoul, Republic of Korea.

7 Institute of Health Services Research, Yonsei University, Seoul, Republic of Korea

Correspondence to: Sung-In Jang, Department of Preventive Medicine, Institute of Health Services Research, Yonsei University College of Medicine, 50 Yonsei-ro, Seodaemun-gu, Seoul 120-752, Republic of Korea. [E-mail: JANGSI@yuhs.ac]. 
methods to assess the prevalence of dental caries, is 2.08 in a 12-year-old child in Korea; this is higher than the index in Japan, the United States, Germany, and Finland (with indices of 1.40, 1.19, 0.70, and 0.70, respectively) (7). Considering the high prevalence of dental caries in children in Korea and the high public health burden of the complications related to dental caries, prophylaxis is crucial.

A previous study reported that five factors on individual, family, and community levels cause dental caries: (i) genetic and biological factors; the (ii) social and (iii) physical environment; (iv) health-related behaviors; and (v) dental and medical care (8). Parents play a major role in maintaining and promoting the oral health of their children. Parents' socioeconomic characteristics, oral hygiene knowledge, oral health behaviors, and beliefs have been shown to be closely related to their children's oral health status $(9,10)$.

The effects of long working hours, shift work, as well as occupational classification and status on the health outcomes of workers have been investigated in several studies. Long working hours are associated with diabetes mellitus (11), cardiovascular disease (12), and depression (13). Shift workers have been shown to be more vulnerable to sleep disorders (14), cancer (15), and periodontal disease (16). However, data on the associations between parents' occupational characteristics and their children's health outcomes are scarce. Maternal occupation has been reported to be associated with health outcomes and birth defects in newborns $(17,18)$. However, these studies focused on the effect of occupational exposure during the perinatal period of newborns. Other studies examined the relationship between parents' occupational characteristics and body mass index (19), depressive symptoms (20), and Crohn's disease (21) in their children.

However, few studies examined the effect of parents' occupational characteristics on their children's dental health. An association between the risk of dental caries among children and their parents' employment status has been reported $(22,23)$. Llompart et al (24) reported that children of manual workers had a higher risk for dental caries than those of employees (in the administration, finance, personal, and security service sectors) in Argentina. However, their analysis was not adjusted for occupational factors such as working hours and work schedules, and the occupational classification was rather crude.

The aim of this population-based study was to examine the association between parents' occupational characteristics (working hours, shift work, occupational characteristics, and occupational status) and untreated dental caries in their children using data from the Korean National Health and Nutrition Examination Survey (KNHANES IV, V, and VI; 2008-2015).

\section{Methods}

\section{Study design and participants}

We analyzed data from the fourth, fifth, and sixth KNHANES (2008-2015). KNHANES is a cross-sectional, nationally representative, population-based survey on the health and nutritional status of Korean residents and is conducted annually by the Korea Centers for Disease Control and Prevention (KCDC). We excluded the 2007 survey year due to lack of data on the working hours of part-time workers. Participants are chosen using a stratified, multistage, probability-cluster design based on age group, geographical area, and sex. Trained interviewers conduct surveys and administer questionnaires regarding socioeconomic characteristics, health-related behaviors, and medical history. The response rate of the survey was $78.4 \%$ in KNHANES IV, $80.8 \%$ in KNHANES V, and $78.3 \%$ in KNHANES VI. A detailed description of the survey has been published previously (25).

Of the 68758 participants who completed KNHANES IV (2008-2009), V (2010-2012), and VI (2013-2015), we selected 10569 children aged $7-18$ years who had no missing data on dental caries of the permanent teeth. The definition of child used by the World Health Organization (WHO) is a person $<19$ years of age (26). We excluded children aged $<7$ years because permanent teeth usually begin to erupt between 6-7 years (27).

We merged the data of mother/father and their child(ren) using the parent's ID variable in the child's data (when available) based on the survey year. We excluded parents who did not currently work by asking the following question: "Have you worked $\geq 1$ hour during the last week for income purposes or worked as an unpaid family worker for $>18$ hours for the last week?" In the final analysis, we evaluated data of 4764 children matched to their mothers and of 5862 children matched to their fathers (after excluding 4 and 31 participants due to missing values for covariates for mothers and fathers, respectively). Since 3146 children overlapped between the mother- and father-matched samples, a total of 7480 children were evaluated in our study.

\section{Sociodemographic characteristics}

The age and sex of the children and parents as well as the sociodemographic characteristics of the parents (cohabitation status, education, and household income) were included as confounders. The children's and parents' ages were divided into three groups: 7-10,11-14, and 15-18 years; and 27-39, 40-44, and 45-59 years, respectively. Cohabitation status was classified as cohabiting (married and living together) versus not cohabiting (not married, married but not living together, divorced, or refusal to answer). Monthly household income was classified 
into quartiles and defined as "highest", "higher-middle", "lower-middle", and "lowest". The parents' educational level was categorized into middle school or lower, high school, and college or higher.

\section{Occupational characteristics}

The parents' occupational characteristics were surveyed through a self-reported questionnaire. Working hours/ week were divided into two groups: normal working hours (10-40 hours); and overtime ( $>40$ hours). Overtime working hours were further classified into 41-51 and $\geq 52$ hours. This classification was based on the statutory working hours in the Labor Standard Act (ie, 40 hours/week) and the allowed additional working hours (ie, 12 hours/week) in South Korea (28). Occupations were classified as white-collar (managers and professionals) versus non-white-collar. Non-white-collar was further divided into pink-collar (clerks, service, and sales staff) and blue-collar (agriculture/fishery workers, craft/trades workers, machine operators and assemblers, as well as simple manual workers). Occupational status was classified as wage earner versus non-wage earner. Non-wage earner was divided into self-employed worker or employer and unpaid family worker. Work schedules were classified as daytime versus shift work. Shift work was categorized into evening, night, rotating (rotating 8-, 12- or 24-hour shifts), and irregular shifts (split shift, irregular schedule, and other).

\section{Untreated dental caries in children}

Using methods recommended by the WHO, 12 trained dentists conducted oral examinations using oral mirrors under a dental light at a mobile examination center to investigate the oral health and dental caries status of the participants (29). They assessed the children's DMFT scores, treatment necessity, condition of restoration, and periodontal status [WHO community periodontal index (CPI) of treatment needs: an epidemiological screening test for periodontal treatment needs in populations based on the presence or absence of periodontal pockets, gingival bleeding, and calculus] (29). For four days annually, the dentists attended training sessions that involved pictures of teeth with/without dental caries and simulation patients, which helped them conduct precise examinations of the oral health status of the study participants. It has been shown that the Kappa values for inter-examiner reliability regarding dental health status ranged from 0.71-0.95 (30). The KNHANES guidelines on oral examination defines a "decayed surface of a tooth" as follows: (i) A definite dental cavity to the naked eye, such as a wide range of black discoloration with defect, or dentinal decay visible through enamel, is judged as a "decayed surface"; (ii) If there is suspicion of caries but it cannot be confirmed with just the naked eye, a CPI probe is allowed. If soft dentin is detected by the probe, it is judged as a "decayed surface". Use of an explorer should be avoided as much as possible to prevent destroying the surface undergoing remineralization; (iii) If filling material and caries are present on the same tooth surface, it is judged as a "decayed surface" (30). In our study, we defined patients with untreated dental caries of the permanent teeth as those with at least one permanent tooth with a decayed surface.

\section{Statistical analysis}

We used descriptive analyses to compare the basic characteristics of the children and their parents. The associations between parents' sociodemographic and occupational characteristics and untreated dental caries in their children were examined using the Chi-squared test. Logistic regression analyses were used to determine the associations between the parents' occupational characteristics and the risk of untreated dental caries in their children. Model 1 was adjusted for the age and sex of the children; model 2 was additionally adjusted for the parent's sociodemographic characteristics (age, cohabitation status, household income, and educational level); and the final model (model 3 ) was additionally adjusted for the occupational characteristics of both parents (working hours, shift work, occupational classification, and occupational status). All analyses were conducted using SAS, version 9.4 (SAS Institute, Cary, NC, USA).

\section{Ethics statement}

The study participants and legal representative of the children who were below the legal age of consent provided written informed consent. The data of the KNHANES were released after removal of identifying records for all participants. The Institutional Review Board (IRB) of the KCDC (IRB 2007-02CON-04-P; 2008-04EXP-01-C; 2009-01CON-03-2C; 2010-02CON21-C; 2011-02CON-06-C; 2012-01EXP-01-2C; 2013-07CON-03-4C; 2013-12EXP-03-5C) approved the protocol used by the KNHANES.

\section{Results}

The basic characteristics of the children and their parents are shown in table 1 . The prevalence of untreated dental caries was $18.6 \%$ and $16.4 \%$ in children matched to their mothers and fathers, respectively. A higher proportion of fathers worked overtime hours ( $>40$ hours) compared to mothers $(67.1 \%$ versus $41.4 \%, \mathrm{P}<0.001)$. In the merged data, the proportion of wage earners was 
significantly higher among mothers than fathers $(67.5 \%$ versus $63.5 \%, \mathrm{P}<0.001)$. We found no significant differences for work schedule and occupational classification between the father- and mother-matched data.

Table 2 shows the differences between children with and without untreated dental caries by mother versus father. The age of the children and parental age, cohabitation status, educational level, and monthly household income were significantly associated with untreated dental caries in their children. Occupational factors (work schedule, occupational classification, and occupational status) were also associated with untreated dental caries among the children irrespective of parent. Only for mothers, working overtime was associated with untreated dental caries in children (mother: $\mathrm{P}<0.001$; father: $\mathrm{P}=0.152$ ).

Table 3 presents the adjusted odds ratios (OR) for untreated dental caries among children according to their parents' occupational characteristics. After adjusting for all covariates (model 3), children whose mothers worked overtime ( $>40$ hours/week) had higher odds for untreated dental caries than those whose mothers worked $\leq 40$ hours/week [OR 1.19, 95\% confidence interval (CI) 1.02-1.39]. Moreover, the children of mothers who were self-employed/employers or unpaid family workers had increased odds of untreated dental caries compared to those of mothers who were wage earners (OR 1.18, 95\% CI 1.00-1.39). The OR of untreated dental caries was

Table 1. Sociodemographic and occupational characteristics of the children and their parents according to mother/father.

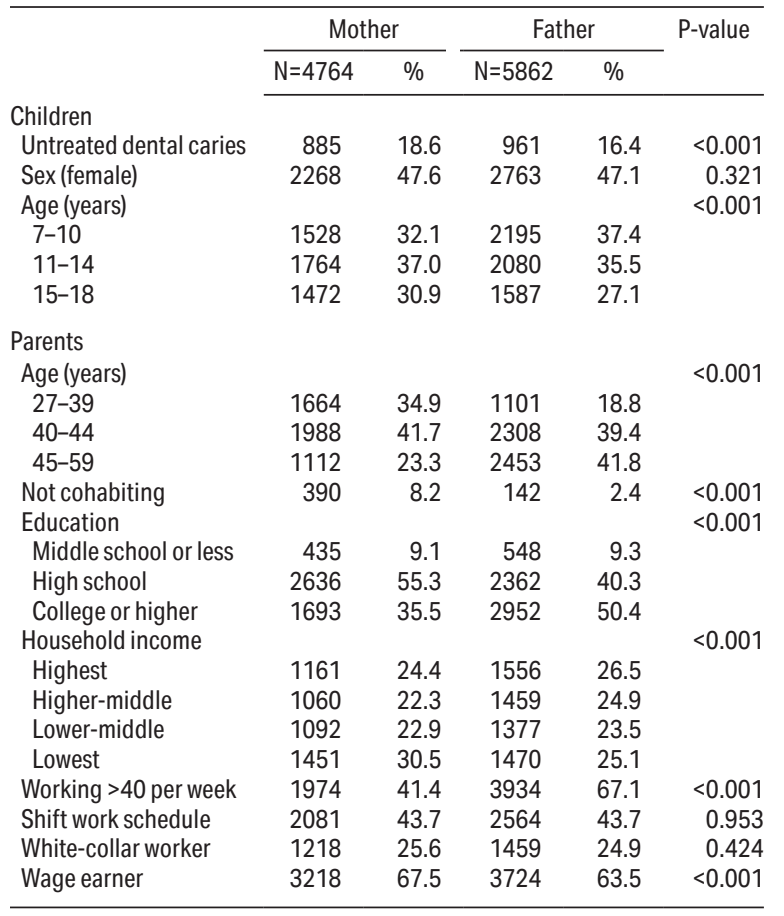

also higher among children with parents who worked shifts compared to those with parents who worked daytime hours (mother: OR 1.29, 95\% CI 1.11-1.51; father: OR $1.36,95 \%$ CI $1.18-1.58)$.

Figure 1 shows the fully adjusted OR for untreated dental caries among children in relation to the detailed occupational characteristics of their parents. Children whose mothers worked $>52$ hours/week compared to $\leq 40$ hours/week had higher odds of untreated dental caries (OR 1.33, 95\% CI 1.09-1.62). The highest OR for untreated dental caries was observed for children of mothers who worked overnight shifts (OR 1.88, 95\% CI 1.12-3.13), followed those whose mothers worked irregular shifts (OR 1.26, 95\% CI 1.06-1.49), compared to daytime hours. Children whose mothers were selfemployed/employers compared to wage earners had increased odds of untreated dental caries (OR 1.20, 95\% CI 1.00-1.46). Children whose fathers were irregular shift workers had a higher adjusted OR for untreated dental caries than those whose fathers were wage earners (OR 1.46, 95\% CI 1.25-1.70). Children whose fathers were blue-collar workers were more likely to have untreated dental caries than those whose fathers who were white-collar workers (OR 1.26, 95\% CI 1.01-1.58.

\section{Discussion}

This study examined the associations between parents' occupational characteristics and untreated dental caries among their children. We show that of mothers' occupational characteristics, working overtime hours, shift work, and being a non-wage earner were significantly associated with untreated dental caries in offspring. For fathers, we only found a significant association between shift work and untreated dental caries in their children.

A previous study revealed an association between mothers working overtime and obesity in their children. Girls aged 6-12 years of mothers who worked 49-60 hours/week were more overweight than girls whose mothers worked 40-48 hours/week (19). Our results similarly showed that the OR of untreated dental caries in children was high when the mother's working hours were long ( $>40$ hours/week). Mothers who work overtime have been shown to have a high tendency of experiencing stress or burnout compared to mothers who work regular working hours (31), which can weaken the mother-child relationship as a result of the mothers' experience of psychological energy depletion (32). Burnout in the mother and a poor mother-child relationship might cause the mother to neglect the correction and adjustment of their children's oral health behaviors; moreover, the mother might fail to bring her children to regular check-ups at the dentist. Good 
Table 2. Sociodemographic and occupational characteristics of children and parents according to untreated dental caries status of the children.

\begin{tabular}{|c|c|c|c|c|c|c|c|c|c|c|}
\hline & \multicolumn{5}{|c|}{ Mother $(\mathrm{N}=4764)$ dental caries of offspring } & \multicolumn{5}{|c|}{ Father ( $N=5862$ ) dental caries of offspring } \\
\hline & \multicolumn{2}{|c|}{ No } & \multicolumn{2}{|c|}{ Yes } & \multirow[t]{2}{*}{ P-value } & \multicolumn{2}{|c|}{ No } & \multicolumn{2}{|c|}{ Yes } & \multirow[t]{2}{*}{ P-value } \\
\hline & $\mathrm{N}$ & $\%$ & $\mathrm{~N}$ & $\%$ & & $\mathrm{~N}$ & $\%$ & $\mathrm{~N}$ & $\%$ & \\
\hline \multicolumn{11}{|l|}{ Children } \\
\hline Sex & & & & & 0.637 & & & & & 0.998 \\
\hline Male & 2026 & 81.2 & 470 & 18.8 & & 2591 & 83.6 & 508 & 16.4 & \\
\hline Female & 1853 & 81.7 & 415 & 18.3 & & 2310 & 83.6 & 453 & 16.4 & \\
\hline Age (years) & & & & & $<0.001$ & & & & & $<0.001$ \\
\hline $7-10$ & 1424 & 93.2 & 104 & 6.8 & & 2059 & 93.8 & 136 & 6.2 & \\
\hline $11-14$ & 1420 & 80.5 & 344 & 19.5 & & 1711 & 82.3 & 369 & 17.7 & \\
\hline $15-18$ & 1035 & 70.3 & 437 & 29.7 & & 1131 & 71.3 & 456 & 28.7 & \\
\hline \multicolumn{11}{|l|}{ Parents } \\
\hline Age (years) & & & & & $<0.001$ & & & & & $<0.001$ \\
\hline $27-39$ & 1448 & 87.0 & 104 & 13.0 & & 1005 & 91.3 & 96 & 8.7 & \\
\hline $40-44$ & 1606 & 80.8 & 344 & 19.2 & & 2004 & 86.8 & 304 & 13.2 & \\
\hline $45-59$ & 825 & 74.2 & 437 & 25.8 & & 1892 & 77.1 & 561 & 22.9 & \\
\hline Cohabitation status & & & & & $<0.001$ & & & & & $<0.001$ \\
\hline Cohabiting & 3586 & 82.0 & 788 & 18.0 & & 4812 & 84.1 & 908 & 15.9 & \\
\hline Not cohabiting & 293 & 75.1 & 97 & 24.9 & & 89 & 62.7 & 53 & 37.3 & \\
\hline Education & & & & & $<0.001$ & & & & & $<0.001$ \\
\hline Middle school or less & 286 & 65.7 & 149 & 34.3 & & 385 & 70.3 & 163 & 29.7 & \\
\hline High school & 2118 & 80.3 & 518 & 19.7 & & 1935 & 81.9 & 427 & 18.1 & \\
\hline College or higher & 1475 & 87.1 & 218 & 12.9 & & 2581 & 87.4 & 371 & 12.6 & \\
\hline Household income & & & & & $<0.001$ & & & & & $<0.001$ \\
\hline Highest & 984 & 84.8 & 177 & 15.2 & & 1349 & 86.7 & 207 & 13.3 & \\
\hline Higher-middle & 887 & 83.7 & 173 & 16.3 & & 1250 & 85.7 & 209 & 14.3 & \\
\hline Lower-middle & 886 & 81.1 & 206 & 18.9 & & 1141 & 82.9 & 236 & 17.1 & \\
\hline Lowest & 1122 & 77.3 & 329 & 22.7 & & 1161 & 79.0 & 309 & 21.0 & \\
\hline Working hours & & & & & $<0.001$ & & & & & 0.152 \\
\hline$\leq 40$ & 2339 & 83.8 & 451 & 16.2 & & 1631 & 84.6 & 297 & 15.4 & \\
\hline$>40$ & 1540 & 78.0 & 434 & 22.0 & & 3270 & 83.1 & 664 & 16.9 & \\
\hline $41-52$ & 848 & 81.9 & 188 & 18.1 & $<0.001^{\text {a }}$ & 1646 & 84.0 & 313 & 16.0 & $0.113^{\mathrm{a}}$ \\
\hline$>52$ & 692 & 73.8 & 246 & 26.2 & & 1624 & 82.2 & 351 & 17.8 & \\
\hline Work schedule & & & & & $<0.001$ & & & & & $<0.001$ \\
\hline Day & 2237 & 83.4 & 446 & 16.6 & & 2828 & 85.7 & 470 & 14.3 & \\
\hline Shift & 1642 & 78.9 & 439 & 21.1 & & 2073 & 80.9 & 491 & 19.1 & \\
\hline Evening & 330 & 81.1 & 77 & 18.9 & $<0.001^{b}$ & 173 & 83.6 & 34 & 16.4 & $<0.001^{b}$ \\
\hline Night & 58 & 70.7 & 24 & 29.3 & & 85 & 81.0 & 20 & 19.0 & \\
\hline Rotating & 70 & 75.3 & 23 & 24.7 & & 238 & 85.6 & 40 & 14.4 & \\
\hline Irregular & 1184 & 79.0 & 315 & 21.0 & & 1577 & 80.0 & 397 & 20.0 & \\
\hline Occupational classification & & & & & $<0.001$ & & & & & $<0.001$ \\
\hline White-collar & 1053 & 86.4 & 165 & 13.6 & & 1264 & 86.6 & 195 & 13.4 & \\
\hline Non-white-collar & 2826 & 79.7 & 720 & 20.3 & & 3637 & 82.6 & 766 & 17.4 & \\
\hline Pink-collar & 1892 & 80.0 & 473 & 20.0 & $<0.001^{\mathrm{C}}$ & 1851 & 86.7 & 285 & 13.3 & $<0.001^{c}$ \\
\hline Blue-collar & 934 & 79.1 & 247 & 20.9 & & 1786 & 78.8 & 481 & 21.2 & \\
\hline Occupational status & & & & & $<0.001$ & & & & & $<0.001$ \\
\hline Wage earner & 2654 & 82.5 & 564 & 17.5 & & 3174 & 85.2 & 550 & 14.8 & \\
\hline Non-wage earner & 1225 & 79.2 & 321 & 20.8 & & 1727 & 80.8 & 411 & 19.2 & \\
\hline Self-employed or employer & 861 & 78.8 & 232 & 21.2 & $0.021^{d}$ & 1654 & 81.0 & 389 & 19.0 & $<0.001^{d}$ \\
\hline Unpaid family worker & 364 & 80.4 & 89 & 19.6 & & 73 & 76.8 & 22 & 23.2 & \\
\hline
\end{tabular}

${ }^{a}$ Chi-squared between $\leq 40,41-52$, and $>52$ working hours/week.

${ }^{\mathrm{b}}$ Chi-squared between day, evening, night, rotating, and irregular shifts.

c Chi-squared between white-collar, pink-collar, and blue-collar.

${ }^{\mathrm{d}}$ Chi-squared between wage earner, self-employed worker/employer, and unpaid family worker.

oral health behaviors such as a low consumption of sugar-containing foods, tooth-brushing (33), and regular dental check-ups (34) can prevent dental caries. Furthermore, application of fluoride varnish, which is routinely performed in Korea during regular dental check-ups, is helpful in preventing dental caries (35).

Our study shows that the children of shift workers were at higher odds of dental caries than those of daytime workers. Our data also showed that children of parents who worked irregular shifts, compared to daytime hours, were at higher odds of untreated dental caries. A previous study showed that shift work in fathers was associated with depressive symptoms and low self-esteem in their children (20). In turn, psychiatric illnesses such as depression and anxiety are related to increased dental decay (36). Previous research showed that shift work in parents was associated with a weak parent-adolescent relationship $(37,38)$. Poor parent- 
Table 3. Logistic regression analysis of the association between parents' occupational characteristics and untreated dental caries in their children. [OR=odds ratio; $\mathrm{Cl}=$ confidence interval.]

\begin{tabular}{|c|c|c|c|c|c|c|}
\hline & \multicolumn{2}{|c|}{ Model1 ${ }^{\text {a }}$} & \multicolumn{2}{|c|}{ Model $2^{\mathrm{b}}$} & \multicolumn{2}{|c|}{ Model3 ${ }^{\circ}$} \\
\hline & OR & $95 \% \mathrm{Cl}$ & OR & $95 \% \mathrm{Cl}$ & OR & $95 \% \mathrm{Cl}$ \\
\hline \multicolumn{7}{|l|}{ Mother } \\
\hline \multicolumn{7}{|l|}{ Working hours } \\
\hline$\leq 40$ & 1.00 & ref & 1.00 & ref & 1.00 & \\
\hline$>40$ & 1.33 & $1.15-1.55$ & 1.24 & $1.06-1.44$ & 1.19 & $1.02-1.3$ \\
\hline \multicolumn{7}{|l|}{ Shift work } \\
\hline No & 1.00 & ref & 1.00 & ref & 1.00 & \\
\hline Yes & 1.41 & $1.22-1.64$ & 1.32 & $1.13-1.54$ & 1.29 & $1.11-1$. \\
\hline White-collar & 1.00 & ref & 1.00 & ref & 1.00 & \\
\hline Non-wt & 1.42 & $1.18-1.72$ & 1.05 & $0.84-1.32$ & 1.04 & $0.83-1.31$ \\
\hline Wage & 1.00 & ref & 1.00 & ref & 1.00 & \\
\hline Non-wage & 1.21 & $1.04-1.42$ & 1.24 & $1.06-1.45$ & 1.18 & $1.00-1$ \\
\hline \multicolumn{7}{|l|}{$\begin{array}{l}\text { Father } \\
\text { lat }\end{array}$} \\
\hline \multicolumn{7}{|l|}{ Working hours } \\
\hline$\leq 40$ & 1.00 & ref & 1.00 & ref & 1.00 & \\
\hline$>40$ & 1.13 & $0.97-1.32$ & 1.13 & $0.96-1.32$ & 1.12 & $0.95-1.31$ \\
\hline \multicolumn{7}{|l|}{ Shift work } \\
\hline No & 1.00 & ref & 1.00 & ref & 1.00 & \\
\hline Yes & 1.46 & $1.27-1.69$ & 1.36 & $1.18-1.58$ & 1.36 & $1.18-1.5$ \\
\hline White-collar & 1.00 & ref & 1.00 & ref & 1.00 & \\
\hline Non-white-collar ${ }^{d}$ & 1.36 & $1.15-1.62$ & 1.06 & $0.88-1.29$ & 1.07 & $0.88-1.3$ \\
\hline Wage earner & 1.00 & ref & 1.00 & ref & 1.00 & \\
\hline Non-wage earnere & 1.20 & $1.04-1.39$ & 1.14 & $0.98-1.33$ & 1.13 & $0.97-1.3$ \\
\hline
\end{tabular}

adjusted for age and sex of the children.

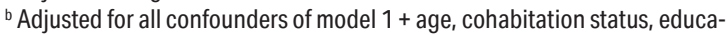
tion, and household income of the mother.

c Adjusted for all confounders of model $2+$ other occupational characteristics (working hours, shift work, occupational classification, and occupational status of the mother).

${ }^{d}$ Includes pink-collar (clerks, service, and sales staff) and blue-collar (agriculture/fishery workers, craft/trades workers, machine operators and assemblers, as well as simple manual workers).

${ }^{\mathrm{e}}$ Includes self-employed workers or employers and unpaid family workers.

child interactions might be associated with a failure of parents to teach their children good oral health behaviors and bring them to the dentist, which might result in untreated dental caries in their children.

In this study, children whose mothers were non-wage earners had higher odds of untreated dental caries than those whose mothers were wage earners. In Korea, the majority of self-employed workers are shop/restaurant owners and not skilled workers; these individuals are confronted with a high risk of losing their business (39). Unstable working conditions can cause stress and depressive symptoms among parents (40), which is linked to stress in their children (41). A previous study showed that perceived stress among students was associated with an increased risk of dental caries (42).

In this study, we found differences between the effects of mothers' and fathers' occupational characteristics on dental caries in their children. Whereas long mothers' working hours or night shifts were related to their children's dental caries, this was not the case for fathers. Worldwide, mothers are typically required to take on the majority of childcare, irrespective of their occupation $(43,44)$. In a study of 66 countries, the time women spent on childcare was on average 3.3

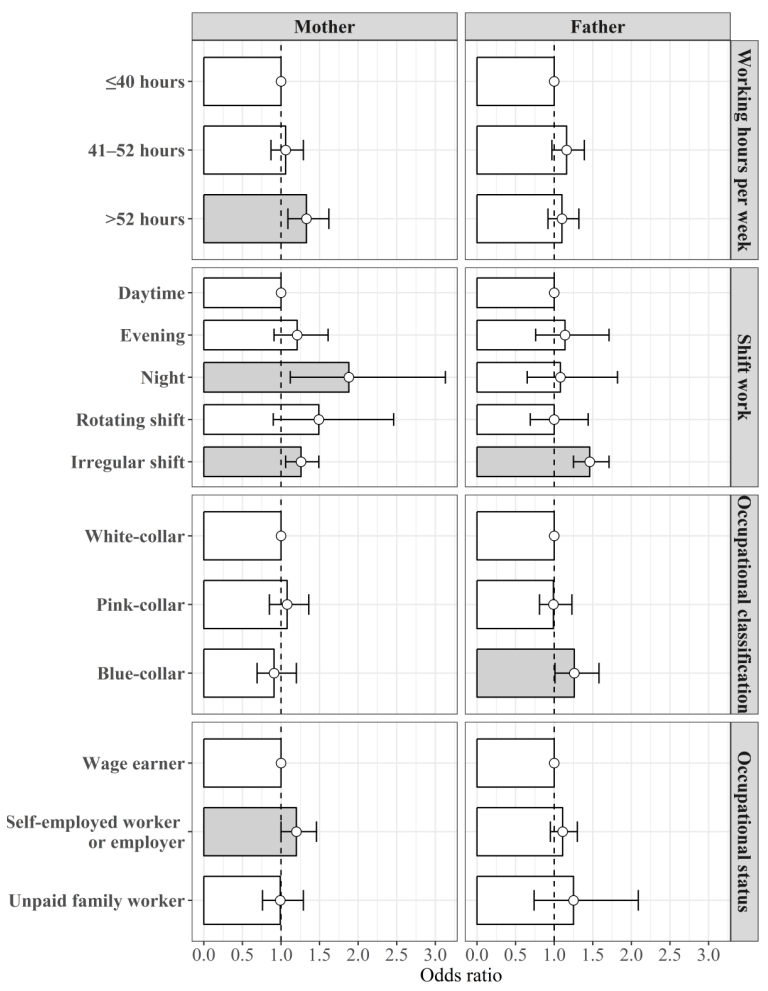

Figure 1. Fullyadjusted logistic regression model (model3) of theassociation between the detailed parents' occupational characteristics and untreated dental caries in their children.

times higher than men (45). Therefore, little free time in mothers might negatively affect the dental health of children more so than a lack of free time in fathers. Furthermore, our study revealed that children whose fathers were blue- compared to white-collar workers were at higher odds for dental caries; this is in line with a previous study that showed children of manual workers had higher odds for dental caries than those of employees (24). We did not find this association in mothers. In our study, the proportion of parents who reported middle school or lower as their highest educational level was higher among fathers than mothers who were blue-collar workers (19.4\% versus $9.3 \%$, respectively; $\mathrm{P}<0.001$; data not shown). Considering that dental caries in children and low parental educational level are closely related $(9,10)$, the low educational level of blue-collar working fathers might have adversely affected the oral health of their children.

The main strength of our study is that it is a population-based study drawing from a well-established and nationally representative dataset published by an official institution. The diagnosis of untreated dental caries was reliable as the dentists diagnosed dental caries after training according to WHO guidelines.

However, our results should be interpreted within the context of the study's limitations. As this was a cross- 
sectional study, we could not establish a causal relationship between parents' occupational characteristics and untreated dental caries in their children. Second, dental caries was diagnosed by a dentist through inspection and percussion; oral radiographs were not used. Our study might have missed some cases of dental caries and therefore underestimated its prevalence. However, identifying dental caries through inspection and percussion is a routine diagnostic tool due to its cost effectiveness and non-reliance on specialized devices. Third, we did not adjust for confounding variables such as the intake of simple sugars, tooth brushing, and regular dental check-ups, which are important risk factor for dental caries. Moreover, the spouse's employment status was not considered in our study; the spouse's employment status might affect the oral health of the children. Fourth, when classifying the parents' work schedule, we might have overestimated the number of workers working irregular shifts, as "other" was included in this group.

In conclusion, working overtime hours, shift work, and being a non-white-collar worker or non-wage earner in parents was associated with higher odds of untreated dental caries in the children. The effects of parental occupational characteristics on untreated dental caries in their children differed by the sex of the parent (mother versus father). Future studies should identify the mediators between parents' occupational characteristics and untreated dental caries in their children. Public health programs targeting the prevention of dental caries in children should consider the occupational characteristics of their parents.

\section{Acknowledgments}

We would like to thank the participants, investigators, and dentists of KNHANES IV, V, and VI as well as the scientists from the Korean Centers for Disease Control and Prevention who collected and handled the KNHANES data.

\section{Conflict of interest and funding}

The authors declare no conflicts of interests. This study received no funding.

\section{References}

1. Selwitz RH, Ismail AI, Pitts NB. Dental caries. Lancet 2007 Jan;369(9555):51-9. http://dx.doi.org/10.1016/S01406736(07)60031-2.

2. Marsh PD. Dental plaque as a biofilm: the significance of

$\mathrm{pH}$ in health and caries. Compend Contin Educ Dent 2009 Mar;30(2):76-8.

3. Aida J, Ando Y, Akhter R, Aoyama H, Masui M, Morita M. Reasons for permanent tooth extractions in Japan. J Epidemiol 2006 Sep;16(5):214-9. http://dx.doi.org/10.2188/ jea.16.214.4. Taiwo AO, Ibikunle AA, Braimah RO, Sulaiman OA, Gbotolorun OM. Tooth extraction: pattern and etiology from extreme Northwestern Nigeria. Eur J Dent 2017 Jul-Sep;11(3):335-9.

5. WHO. Global Consultation on Oral Health through [Geneva, Switzerland/Ferney-Voltaire, France: World Health Organization in collaboration with the International Dental Federation and International Association for Dental Research.]. Fluoride 2006 Nov:17-9.

6. Kim AH, Shim YS, Kim JB, An SY. Caries Prevalence in Korean Children and Adolescents from 2000 to 2012. J Clin Pediatr Dent 2017;41(1):32-7. http://dx.doi. org/10.17796/1053-4628-41.1.32.

7. Bernabé E, Sheiham A. Extent of differences in dental caries in permanent teeth between childhood and adulthood in 26 countries. Int Dent J 2014 Oct;64(5):241-5. http://dx.doi. org/10.1111/idj.12113.

8. Fisher-Owens SA, Gansky SA, Platt LJ, Weintraub JA, Soobader MJ, Bramlett MD et al. Influences on children's oral health: a conceptual model. Pediatrics 2007 Sep;120(3):e510-20. http://dx.doi.org/10.1542/peds.20063084 .

9. Kumar S, Tadakamadla J, Kroon J, Johnson NW. Impact of parent-related factors on dental caries in the permanent dentition of 6-12-year-old children: A systematic review. J Dent 2016 Mar;46:1-11. http://dx.doi.org/10.1016/j. jdent.2015.12.007.

10. Cianetti S, Lombardo G, Lupatelli E, Rossi G, Abraha I, Pagano $\mathrm{S}$ et al. Dental caries, parents educational level, family income and dental service attendance among children in Italy. Eur J Paediatr Dent 2017 Mar;18(1):15-8.

11. Kivimäki M, Virtanen M, Kawachi I, Nyberg ST, Alfredsson L, Batty GD et al. Long working hours, socioeconomic status, and the risk of incident type 2 diabetes: a metaanalysis of published and unpublished data from 222 120 individuals. The lancet Diabetes \& endocrinology. 2015;3(1):27-34.

12. Kivimäki M, Jokela M, Nyberg ST, Singh-Manoux A, Fransson EI, Alfredsson L et al. Long working hours and risk of coronary heart disease and stroke: a systematic review and meta-analysis of published and unpublished data for 603 838 individuals. The Lancet. 2015;386(10005):1739-46.

13. Nakata A. Work hours, sleep sufficiency, and prevalence of depression among full-time employees: a community-based cross-sectional study. J Clin Psychiatry 2011 May;72(5):60514. http://dx.doi.org/10.4088/JCP.10m06397gry.

14. Fekedulegn D, Burchfiel CM, Charles LE, Hartley TA, Andrew ME, Violanti JM. Shift Work and Sleep Quality Among Urban Police Officers: the BCOPS Study. J Occup Environ Med 2016 Mar;58(3):e66-71. http://dx.doi. org/10.1097/JOM.0000000000000620. 
15. Vistisen HT, Garde AH, Frydenberg M, Christiansen P, Hansen AM, Andersen J et al. Short-term effects of night shift work on breast cancer risk: a cohort study of payroll data. Scand J Work Environ Health 2017 Jan;43(1):59-67. http://dx.doi.org/10.5271/sjweh.3603.

16. Han DH, Khang YH, Jung-Choi K, Lim S. Association between shift work and periodontal health in a representative sample of an Asian population. Scand J Work Environ Health 2013 Nov;39(6):559-67. http://dx.doi.org/10.5271/ sjweh.3370.

17. Shaw GM, Nelson V, Olshan AF. Paternal occupational group and risk of offspring with neural tube defects. Paediatr Perinat Epidemiol 2002 Oct;16(4):328-33. http://dx.doi. org/10.1046/j.1365-3016.2002.00436.x.

18. Schnitzer PG, Olshan AF, Erickson JD. Paternal occupation and risk of birth defects in offspring. Epidemiology 1995 Nov;6(6):577-83. http://dx.doi.org/10.1097/00001648199511000-00003.

19. Lee G, Kim HR. Mothers' Working Hours and Children's Obesity: Data from the Korean National Health and Nutrition Examination Survey, 2008-2010. Ann Occup Environ Med 2013 Oct;25(1):28. http://dx.doi.org/10.1186/2052-437425-28.

20. Barton J, Aldridge J, Smith P. The emotional impact of shift work on the children of shift workers. Scand J Work Environ Health 1998;24 Suppl 3:146-50.

21. Eslahpazir J, Kumar R, Lalavi A, Amre DK. Parental occupations and risk for Crohn's disease in children. Scand J Gastroenterol 2017 Oct;52(10):1093-8. http://dx.doi.org/ 10.1080/00365521.2017.1339826.

22. Enjary C, Tubert-Jeannin S, Manevy R, Roger-Leroi V, Riordan PJ. Dental status and measures of deprivation in Clermont-Ferrand, France. Community Dent Oral Epidemiol 2006 Oct;34(5):363-71. http://dx.doi.org/10.1111/j.16000528.2006.00284.x.

23. Daneshkazemi AR, Davari A. Assessment of DMFT and enamel hypoplasia among junior high school children in Iran. J Contemp Dent Pract 2005 Nov;6(4):85-92.

24. Llompart G, Marin GH, Silberman M, Merlo I, Zurriaga O; GIS (Grupo Interdisciplinario para Salud). Oral health in 6-year-old schoolchildren from Berisso, Argentina: falling far short of WHO goals. Med Oral Patol Oral Cir Bucal 2010 Jan;15(1):e101-5.

25. Kweon S, Kim Y, Jang MJ, Kim Y, Kim K, Choi S et al. Data resource profile: the Korea national health and nutrition examination survey (KNHANES). Int J Epidemiol 2014 Feb;43(1):69-77. http://dx.doi.org/10.1093/ije/dyt228.

26. World Health Organization. HIV/AIDS/Definition of key terms. Available from: http://www.who.int/hiv/pub/ guidelines/arv2013/intro/keyterms/en/. (accessed 11 October 2017).

27. Association JotAD. For the dental patient. Tooth eruption: The primary teeth. J Am Dent Ass. 2005;136(11):1619.

28. Ministry of Employment and Labor [Internet]. Chapter IV. Working Hours and Recess, Article 50 (Working Hours)
In: Labor Standard Act. 2013. Available from: http://www. moel.go.kr/english/poli/poliLaw_view.jsp?idx $=254 \& \mathrm{tab}=6$. (access 11 October 2017).

29. Organization WH. World Health Organization: oral health surveys, basic methods. Geneva: World Health Organization; 1997.

30. Park DY. Standardization for Oral Health Survey in KNHANES. Osong, Korea Centers for Disease Control and Prevention, 2016.

31. Takayama Y, Suzuki E, Kobiyama A, Maruyama A, Sera Y. Factors related to the burnout of Japanese female nurses with children under 3 years old. Jpn J Nurs Sci 2017 Jul;14(3):240-54. http://dx.doi.org/10.1111/jjns.12153.

32. Hagelskamp C, Hughes DL. Linkages between mothers' job stressors and adolescents' perceptions of the mother-child relationship in the context of weak versus strong support networks. Community Work Fam 2016;19(1):1-22. http:// dx.doi.org/10.1080/13668803.2014.998628.

33. Gibson S, Williams S. Dental caries in pre-school children: associations with social class, toothbrushing habit and consumption of sugars and sugar-containing foods. Further analysis of data from the National Diet and Nutrition Survey of children aged 1.5-4.5 years. Caries Res 1999;33(2):10113. http://dx.doi.org/10.1159/000016503.

34. Kärkkäinen S, Seppä L, Hausen H. Dental check-up intervals and caries preventive measures received by adolescents in Finland. Community Dent Health 2001 Sep;18(3):157-61.

35. Mishra P, Fareed N, Battur H, Khanagar S, Bhat MA, Palaniswamy J. Role of fluoride varnish in preventing early childhood caries: A systematic review. Dent Res J (Isfahan) 2017 May-Jun;14(3):169-76. http://dx.doi. org/10.4103/1735-3327.208766

36. Kisely S, Sawyer E, Siskind D, Lalloo R. The oral health of people with anxiety and depressive disorders - a systematic review and meta-analysis. J Affect Disord 2016 Aug;200:119-32. http://dx.doi.org/10.1016/j. jad.2016.04.040

37. Davis KD, Crouter AC, McHale SM. Implications of shift work for parent $\square$ adolescent relationships in dual $\square$ earner families. Fam Relat 2006;55(4):450-60. http://dx.doi. org/10.1111/j.1741-3729.2006.00414.x.

38. Han WJ. Shift work and child behavioral outcomes. Work Employ Soc 2008 Mar;22(1):67-87. http://dx.doi. org/10.1177/0950017007087417.

39. Park H. The stability of self-employment: A comparison between Japan and Korea. Int Sociol 2010;25(1):98-122. http://dx.doi.org/10.1177/0268580909346708.

40. Bosmans K, Hardonk S, De Cuyper N, Vanroelen C. Explaining the relation between precarious employment and mental well-being. A qualitative study among temporary agency workers. Work 2016;53(2):249-64. http://dx.doi. org/10.3233/WOR-152136

41. Lin X, Zhang Y, Chi P, Ding W, Heath MA, Fang X et al. The Mutual Effect of Marital Quality and Parenting Stress on Child and Parent Depressive Symptoms in Families of Children with Oppositional Defiant Disorder. Front 
Psychol 2017 Oct;8:1810. http://dx.doi.org/10.3389/ fpsyg.2017.01810.

42. Jain M, Singh A, Sharma A. Relationship of Perceived Stress and Dental Caries among Pre University Students in Bangalore City. J Clin Diagn Res 2014 Nov;8(11):ZC131-4.

43. Charmes J. Time Dedicated to Child Care, Care Work and Unpaid Work in Total Work Time: Findings of an international compendium on 65 countries and 102 surveys, documento de información del ODI. Londres: ODI. 2016.
44. Samman E, Presler-Marshall E, Jones N. Women's work: mothers, children and the global childcare crisis. London: Overseas Development Institute. 2016.

45. Charmes J. Time Use across the World: Findings of a World Compilation of Time-Use Surveys. Documento de trabajo PNUDOIDH, Nueva York. 2015.

Received for publication: 5 December 2017 